H.C. Lin $^{2}$, E.F. Corbet ${ }^{1}$, E.C.M. Lo ${ }^{1 *}$, and H.G. Zhang ${ }^{2}$

${ }^{1}$ Faculty of Dentistry, The University of Hong Kong, 3/F, Prince Philip Dental Hospital, 34 Hospital Road, Hong Kong; and ${ }^{2}$ Department of Preventive Dentistry, Sun Yatsen University of Medical Sciences; * corresponding author, hrdplcm@hkucc.hku.hk

J Dent Res 80(5):1491-1495, 2001

\title{
Tooth Loss, Occluding Pairs, and Prosthetic Status of Chinese Adults
}

\section{INTRODUCTION}

oss of permanent teeth can result from one of two events: Either teeth are extracted by oral health care providers, or else the progression of oral diseases is such that teeth are lost spontaneously. In the case of dental caries, teeth may be broken down with exfoliation of infected residual roots. In the case of periodontal diseases, teeth may lose all periodontal attachment. Tooth extraction is closely linked to the provision of and access to dental care services. Although the loss of permanent teeth has declined in highly industrialized countries in the past two to three decades (Downer, 1991; Spencer et al., 1994; White et al., 1995), recent surveys have still shown more missing teeth among adults in the industrialized countries (Kalsbeek et al., 1991; Loh et al., 1996; Marcus et al., 1996; Micheelis and Bauch, 1996) than among adults in many developing countries, including China (Baelum and Fejerskov, 1986; Manji et al., 1988; Luan et al., 1989; Petersen and Razanamihaja, 1996; Petersen and Kaka, 1999). People living in developing countries, especially those living in rural areas, have less access to dental care services than the urban dwellers of those countries and less than those living in industrialized countries. Therefore, it is assumed that this lack of access to dental care services will result in more teeth which should be extracted but which, on clinical examination, still remain in the mouth in subjects of these populations, and that, among the remaining teeth, more non-functional teeth will be detected. Some authors have mentioned the state of "teeth indicated for extraction" in developing countries when they described the conditions with respect to tooth loss (Manji et al., 1988; Luan et al., 1989; Ekanayaka, 1984).

In an evaluation of the function of dentitions, occluding tooth pairs could be a more direct index than the number of teeth present (Battistuzzi et al., 1987). Käyser $(1984,1989)$ suggested that elderly people in Europe may be able to function at an acceptable, if suboptimal, level with a reduced dentition consisting of 10 occluding pairs, and that 8 occluding pairs at age 70 years and above could provide minimal function (Käyser, 1989). This Shortened Dental Arch (SDA) concept has recently been reviewed (Witter et al., 1999), and it is acknowledged that the proposal for the SDA is based on circumstantial evidence. The shortened dental arch has been studied in an epidemiological survey only in a supplementary analysis from the 1988 adult dental health survey of England (Gordon et al., 1994). and its prevalence has been studied in older Canadian adults (Hawkins, 1998). However, apart from these, further epidemiological studies supplying data about the number of existing occluding tooth pairs in relation to age are scarce.

Tooth loss and prosthetic treatment patterns among Hong Kong Chinese (Corbet and Lo, 1994; Lo and Schwarz, 1994) and among urban and rural residents of Northern China (Baelum et al., 1988; Luan et al., 1989) have been reported. A survey in the Beijing area found that a partial denture was more often seen among urban residents than among rural residents, whereas the reverse tendency was seen for bridges. Reported epidemiological surveys on tooth loss and prosthetic status among residents in Mainland China, especially in those living in rural areas, are still few. The objectives of the present analysis were to describe tooth loss, teeth indicated for extraction, prosthetic status, and occluding tooth pairs in the dentitions of 35- to 44-year-old and 65- to 74-year-old Chinese, from both urban and rural areas in Southern China, and to investigate factors affecting tooth loss in these population groups.
The Oral Health Survey in Southern China, 1997, was conducted under the auspices of the Department of Periodontology and Public Health of the Faculty of Dentistry, the University of Hong Kong, and publication of these papers is made possible by funding from The Research Grants Council of the Hong Kong Special Administrative Region, China, HKU 232/95M, together with the University of Hong Kong Committee for Research and Conference Grants. 
Table 1. Missing Teeth (MT), Indicated Missing Teeth (IMT), and Adjusted Missing Teeth (AMT) among Adult Southern Chinese

\begin{tabular}{|c|c|c|c|c|c|}
\hline Age Group & Location & $\mathrm{n}$ & $\begin{array}{c}\text { MT } \\
\text { Mean (SE) }\end{array}$ & $\begin{array}{c}\text { IMT } \\
\text { Mean (SE) }\end{array}$ & $\begin{array}{c}\text { AMT } \\
\text { Mean (SE) }\end{array}$ \\
\hline \multicolumn{6}{|c|}{ 35- to 44 -year-olds } \\
\hline \multirow[t]{2}{*}{ Men } & Urban & 393 & $2.1(0.1)$ & $0.5^{a}(0.0)$ & $2.6(0.1)$ \\
\hline & Rural & 370 & $2.1(0.1)$ & $0.7(0.1)$ & $2.9(0.2)$ \\
\hline \multirow[t]{2}{*}{ Women } & Urban & 405 & $2.7(0.1)$ & $0.5^{a}(0.1)$ & $3.2^{a}(0.2)$ \\
\hline & Rural & 405 & $2.9(0.1)$ & $1.2(0.1)$ & $4.1(0.2)$ \\
\hline \multirow[t]{2}{*}{ Total } & Urban & 798 & $2.4(0.1)$ & $0.5^{a}(0.0)$ & $2.9^{a}(0.1)$ \\
\hline & Rural & 775 & $2.6(0.1)$ & $1.0(0.1)$ & $3.5(0.1)$ \\
\hline \multicolumn{6}{|c|}{ 65- to 74 -year-olds } \\
\hline \multirow[t]{2}{*}{ Men } & Urban & 391 & $10.9(0.4)$ & $1.7^{a}(0.1)$ & $12.6(0.4)$ \\
\hline & Rural & 368 & $10.5(0.4)$ & $2.9(0.2)$ & $13.5(0.5)$ \\
\hline \multirow[t]{2}{*}{ Women } & Urban & 383 & $12.4^{b}(0.5)$ & $1.8^{a}(0.1)$ & $14.3^{a}(0.5$ \\
\hline & Rural & 373 & $13.9(0.5)$ & $3.6(0.2)$ & $17.5(0.5)$ \\
\hline \multirow[t]{2}{*}{ Total } & Urban & 774 & $11.6(0.3)$ & $1.8^{a}(0.1)$ & $13.4^{a}(0.3$ \\
\hline & Rural & 741 & $12.2(0.3)$ & $3.3(0.1)$ & $15.5(0.3)$ \\
\hline
\end{tabular}

a Significantly different between urban and rural residents, $t$ test, $p<0.01$.

b Significantly different between urban and rural residents, $t$ test, $p<0.05$.
All of the subjects were interviewed by trained interviewers using a structured questionnaire to collect information about the subject's demographic background, perceived oral health conditions, oral health knowledge, attitudes, and practices, and use of dental services. Clinical examinations were completed by one of three calibrated examiners following the procedures and diagnostic criteria recommended by the World Health Organization (1997). Overhead lights, plane mouth mirrors, and CPI probes were used during the clinical examinations. Each tooth was recorded for its status and treatment need. Prosthetic status was recorded for each subject by arch, classified as no prostheses, 1 bridge, 2 or more bridges, partial denture, bridge and partial denture, or complete denture. Only subjects who were wearing or could show their dentures at the examination were recorded as denture-wearers.

Teeth not present for any reason were defined as missing teeth (MT), including third molars. Teeth having a treatment need for extraction, i.e.. teeth indicated for extraction, were recorded. According to the WHO (1997) criteria, a tooth was indicated for extraction when caries had so destroyed the tooth that it could not be restored, when periodontal disease had progressed so far that the tooth could not be restored to a functional state in the clinical judgment

\section{MATERIALS \& METHODS}

The study sample consisted of 1573 35- to 44-year-old and 1515 65- to 74-year-old Chinese living in both urban and rural areas in Guangdong Province, Southern China. Details of the sampling methods and recruitment of subjects have been described in a preceding paper (Schwarz et al., 2001). In brief, 16 sampling sites ( 8 urban and 8 rural sites) were selected through the following method. First, 4 major administrative regions of the Province were chosen for the survey, mainly based on their geographic location. Then, by two-stage stratified random sampling, 2 urban subdistricts and 2 rural townships in each region were selected to be the survey sites. With assistance from the local government and health authority, about 100 subjects in each age group were recruited in each survey site. In urban areas, the 35- to 44-yearolds were recruited from factories and other work places, to include different occupation groups, and the 65- to 74-year-olds were recruited from their homes. In rural areas, subjects were recruited from their homes in the villages.

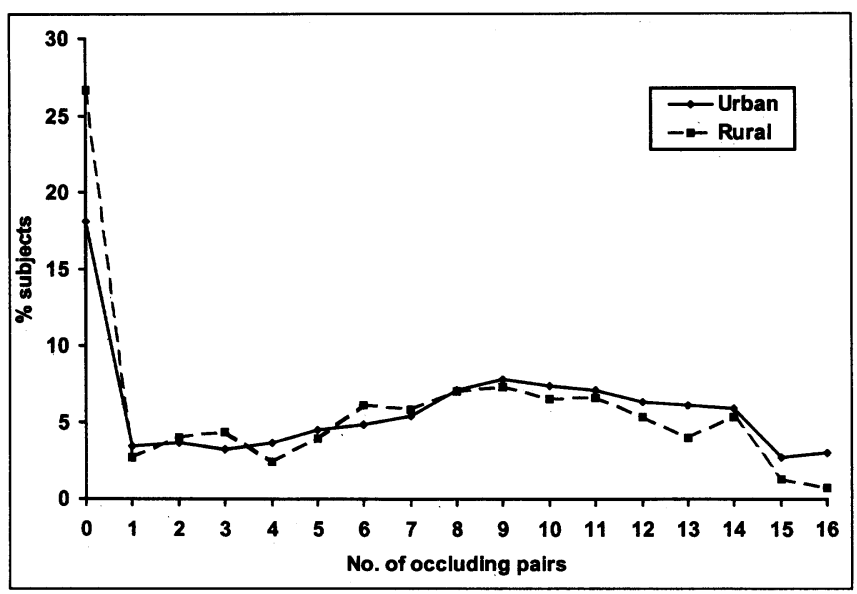

Figure 1. Percentage distribution of the 65- to 74-year-old subjects according to location of residence and number of occluding tooth pairs. of the examiner, when a tooth needed to be extracted to make way for a prosthesis, or when extraction was required for orthodontic or cosmetic reasons or because of impaction. No recording was made, however, of the reason for indicating a tooth as requiring extraction. These teeth indicated for extraction can also be considered to be missing teeth (IMT). The adjusted missing teeth (AMT) was the sum of MT and IMT. Occluding tooth pairs were recorded for the 65- to 74-year-olds only. Occluding tooth pairs were defined as pairs of maxillary and mandibular teeth that came into contact when the subjects closed in centric occlusion; this included bridge abutments and pontics but excluded removable dentures, teeth indicated for extraction, and pontics indicated for removal (because of looseness of bridges or caries in abutments).

Duplicate examinations were carried out on a random $10 \%$ sample of the study subjects throughout the survey. Analysis performed on the duplicate examination recordings gave a kappa statistics of 0.89 for tooth status in both age groups, and the respective figures for prosthetic status in the middle-aged and the elderly were 0.96 and 0.94 . These figures indicated that the inter-examiner reliability was very good (WHO, 1997).

In this study, based on the ICS II model (Schwarz et al., 2001), predisposing, enabling, and health behavior variables determined from the questionnaire-location of residence, gender, education level, dental knowledge score, dental attitude score, dental anxiety, family material possession index (FMPI), toothbrushing frequency, tobaccosmoking habits, time lapsed since last dental visit-which were considered as possible factors that might affect the AMT score, were chosen as independent variables in the analysis of covariance (ANCOVA) for both age groups. The calculation of FMPI (Schwarz et al., 2001) and the calculation of dental knowledge and dental attitude ANCOVA was performed by means of the computer software SAS for Windows, and other analyses were done with SPSS for Windows. The level of statistical significance was set at 0.05 .

\section{RESULTS}

Complete edentulousness was found in $4.4 \%$ of the urban and $3.4 \%$ of the rural 65- to 74-year-olds (Chi-square test, $p>0.05$ ). The scores (Lin et al., 2001a) have been described in preceding papers. 
weighted prevalence of complete edentulousness for Guangdong Province (urban:rural = 1:3) was thus 3.7\%. If the teeth indicated for extraction were to be removed from the calculation, then $5.0 \%$ of the urban elderly and $7.3 \%$ of the rural elderly would be edentulous ( $p>0.05$ ). The weighted prevalence would thus be $5.6 \%$. Only one person in the 35- to 44-year-old age group was edentulous, and she had congenital dental agenesis (complete anodontia). The mean numbers of missing teeth were 2.4 and 2.6 in urban and rural middle-aged, respectively ( $\mathrm{p}>0.05$; weighted MT, 2.6), and 11.6 and 12.2 in urban and rural elderly, respectively $(\mathrm{p}>0.05$; weighted MT, 12.1). However, significantly higher IMT scores were found in rural residents than in urban residents in both men and women of the 2 age groups (Table 1). The highest AMT score was found in rural women in both the 35- to 44-year-olds and the 65- to 74year-olds.

About $40 \%$ of the middle-aged rural women had 4 or more AMT, whereas the corresponding figures were about $20 \%$ in the middle-aged rural men and in urban residents. More obvious differences were found in the 65- to 74-year-olds. About half of the rural women had 16 or more AMT, while only about one-third of the elderly in the other subgroups had such a high AMT score. Nearly all of the 35- to 44-year-olds and half of the 65- to 74-year-olds (except for the rural women) had 20 or more of their teeth remaining and not indicated for extraction, i.e., an AMT score of 12 or less.

In the 35- to 44-year-olds, the teeth most frequently recorded as missing were the third molars (more than $35 \%$ ), and the teeth that were indicated for extraction were mainly molars and premolars. In the 65- to 74-year-olds, the tooth type with the highest percentage of teeth missing or indicated for extraction was molars $(63 \%)$, followed by premolars $(39 \%)$, incisors $(32 \%)$, and canines $(28 \%)$.

The results of ANCOVA on AMT among the 35- to 44-year-olds and the 65- to 74-year-olds are shown in Table 2. Among the 35- to 44-year-olds, it was found that women, smokers, those who had a lower education level, those who had dental anxiety, those who had visited a dentist within 5 years, and those who were less wealthy had higher AMT scores. Bonferroni's multiple comparison could not detect a significant difference among the three education groups, but the difference between the lowest and the highest groups was very close to a statistically significant level $(p=0.05)$. Among the 65 - to 74 year-olds, women, those who had a lower education level, those who did not brush their teeth, and those who were economically less well-off had higher AMT scores.

Only $11.4 \%$ of the urban and $17.5 \%$ of the rural middle-aged were found to have a dental prosthesis (Table 3). Very few complete dentures for an arch were encountered. Among the elderly group, $51.4 \%$ of the urban and $42.6 \%$ of the rural residents presented with a dental prosthesis. Proportions of the elderly with a complete denture were $10.2 \%$ and $7.8 \%$ in urban and rural elderly, respectively. Bridges were more common than partial dentures in both the 35- to 44-year-olds and the 65- to 74-yearolds. In both age groups, wearing a partial denture was more common in urban residents than in rural residents.

The percentage distribution of the 65- to 74-year-old urban and
Table 2. Relationship between Adjusted Missing Teeth (AMT) and Selected Independent Variables (ANCOVA analysis)

\begin{tabular}{|c|c|c|c|c|}
\hline ndependent Variable & Estimate & SE (Estimate) & $\mathrm{p}$-value & $\begin{array}{l}\text { Bonferroni's } \\
\text { Multiple } \\
\text { Comparison }\end{array}$ \\
\hline \multicolumn{5}{|l|}{ (35- to 44 -year-olds $\left.{ }^{a}\right)$} \\
\hline Gender & & & $<0.01$ & \\
\hline \multicolumn{5}{|l|}{ Menc } \\
\hline Women & 1.07 & 0.26 & & \\
\hline Education level & & & $<0.05$ & \\
\hline \multicolumn{5}{|l|}{ No schooling/primaryc } \\
\hline Secondary & -0.43 & 0.20 & & \\
\hline Post-secondary & -0.83 & 0.35 & & \\
\hline Dental anxiety & & & $<0.05$ & \\
\hline \multicolumn{5}{|l|}{ Noc } \\
\hline Yes & 0.39 & 0.18 & & \\
\hline Smoking habits & & & $<0.05$ & \\
\hline \multicolumn{5}{|l|}{ Never been smoker ${ }^{c}$} \\
\hline Smoker/former smoker & 0.54 & 0.26 & & \\
\hline -ast dental visit & & & $<0.01$ & \\
\hline \multicolumn{5}{|l|}{$(1)>5 \mathrm{yrs}^{c}$} \\
\hline (2) $2-5$ yrs & 0.91 & 0.22 & & $(2)>(1)$ \\
\hline$(3)<2$ yrs & 0.64 & 0.18 & & $(3)>(1)$ \\
\hline =MPI & -0.01 & 0.01 & $<0.01$ & \\
\hline (Intercept) & 2.57 & 0.30 & $<0.01$ & \\
\hline \multicolumn{5}{|l|}{ (65- to 74-year-oldsb) } \\
\hline Gender & & & $<0.01$ & \\
\hline \multicolumn{5}{|l|}{ Menc } \\
\hline Women & 1.86 & 0.55 & & \\
\hline Education & & & $<0.05$ & \\
\hline \multicolumn{5}{|l|}{ No schooling ${ }^{c}$} \\
\hline Primary & -1.09 & 0.60 & & $(1)>(3)$ \\
\hline Secondary \& post & -2.28 & 0.78 & & \\
\hline Toothbrushing frequency & & & $<0.01$ & \\
\hline \multicolumn{5}{|l|}{ Once or more a dayc } \\
\hline Less than once a day & 5.89 & 0.77 & & \\
\hline FMPI & -0.04 & 0.02 & $<0.05$ & \\
\hline (Intercept) & 14.27 & 0.59 & $<0.01$ & \\
\hline
\end{tabular}

\footnotetext{
a $\mathrm{F}$-value $=11.87 ; \mathrm{df}=8,1564 ; \mathrm{p}<0.01$

b $F$-value $=28.71 ; d f=5,1509 ; p<0.01$.

Reference category.
}

rural residents according to their numbers of occluding tooth pairs is shown in Fig. 1. Eighteen percent of the urban elderly and $27 \%$ of the rural elderly had no occluding tooth pairs. In both the urban and rural areas, more than half of the elderly had between 7 and 14 occluding tooth pairs. After accounting for IMT, 38\% of the urban elderly and $30 \%$ of the rural elderly had at least 10 occluding pairs. The proportions of the urban and the rural elderly who had 8 or more occluding pairs were $53 \%$ and $44 \%$, respectively.

The questionnaire sought responses to the question: Do you have difficulties in chewing hard foods, such as peanuts? Fig. 2 shows the proportions of respondents claiming difficulties in chewing hard foods by the number of occluding pairs. It can be seen that problems with chewing were more commonly found among the elderly subjects who had fewer than 8 occluding tooth pairs. 


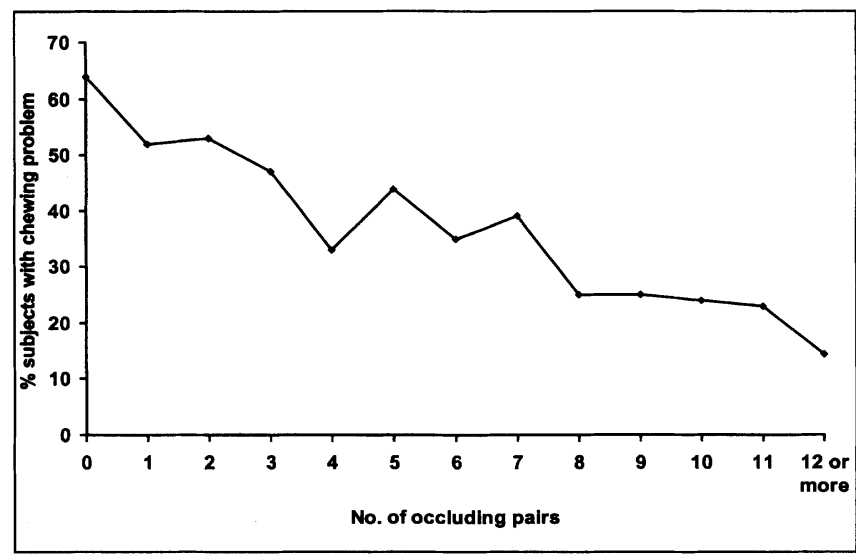

Figure 2. Percentage distribution of 65- to 74-year-old subjects reporting difficulties in chewing by their numbers of occluding tooth pairs.

\section{DISCUSSION}

Findings of the present study showed that almost all of the 35- to 44-year-olds and around half of the 65- to 74-year-olds in Southern China retained 20 or more of their teeth not indicated for extraction. The MT totals for the 35- to 44-year-olds in the present study are similar to the results of a study in the same age group in Western China (Liu et al., 1984), and the MT totals for the 65- to 74-yearolds are similar to those of the elderly in Northern China (Luan et al., 1989) and Western China (Chen et al., 1986), but higher than those found recently in Central China (Petersen et al., 1997). The MT totals of the 2 age groups surveyed in this study were lower than those found in a study of Hong Kong adults (Lo and Schwarz, 1994). Hong Kong people are mainly descendants of Guangdong Province but have higher income and greater access to dental care services than the Cantonese living in Guangdong. When compared with other developing countries, the MT and AMT of the Southern Chinese were similar to those reported for middle-aged adults in Tanzania (Baelum and Fejerskov, 1986) and Kenya (Manji et al., 1988), but lower than those in the middle-aged and the elderly in Sri Lanka (Ekanayaka, 1984). When compared with the findings of recent surveys in industrialized countries in Asia, Europe, and North America (Kalsbeek et al., 1991; Loh et al., 1996; Marcus et al., 1996; Micheelis and Bauch, 1996), the numbers of missing teeth in the Guangdong population were fewer, even after the teeth indicated for extraction had been taken into consideration.

Although urban and rural subjects in this survey had similar numbers of missing teeth, more teeth indicated for extraction were

Table 3. Percentage of Subjects with Dental Prostheses According to Location of Residence

\begin{tabular}{|c|c|c|c|c|}
\hline & \multicolumn{2}{|c|}{ 35- to 44 -year-olds } & \multicolumn{2}{|c|}{65 - to 74 -year-olds } \\
\hline & $\begin{array}{l}\text { Urban } \\
(n=798)\end{array}$ & $\begin{array}{c}\text { Rural } \\
(n=775)\end{array}$ & $\begin{array}{c}\text { Urban } \\
(n=774)\end{array}$ & $\begin{array}{c}\text { Rural } \\
(n=741)\end{array}$ \\
\hline Any prostheses & $11.4^{\mathrm{a}}$ & 17.5 & $51.4^{\mathrm{a}}$ & 42.6 \\
\hline Bridge & $8.0^{a}$ & 17.4 & 35.7 & 37.7 \\
\hline Partial denture & $3.6^{a}$ & 0.4 & $16.5^{\mathrm{a}}$ & 4.2 \\
\hline Complete denture & 0.1 & 0 & 10.2 & 7.8 \\
\hline
\end{tabular}

a Significantly different between urban and rural residents, Chisquare test, $\mathrm{p}<0.01$ detected in the rural adults than in the urban adults. This demonstrates that, in Southern China, poor access to dental care providers in the rural areas leads to accumulation of tooth extraction needs in the population. The present finding that women had more missing teeth than men is in accordance with that of a study on Northern Chinese adults (Luan et al., 1989). Greater tooth loss in women than in men has been found in many countries, but the reasons are still unclear (O'Mullane et al., 1993). In the present study, women have been shown to experience less periodontal disease (Corbet et al., 2001) but more decayed teeth (Lin et al., $2001 \mathrm{~b}$ ). Since caries is the principal cause of tooth loss (Corbet and Davies, 1991; Burt and Eklund, 1992), the greater number of teeth lost among women appears to be related to their caries experience.

Education level and FMPI were found to relate to AMT in both age groups. Those who had attained a higher education level and those who were wealthier had lower AMT scores. These results were consistent with findings from other studies outside China (Kalsbeek et al., 1991; Eklund and Burt, 1994; Miller and Locker, 1994). Smoking has been found to be associated with an increased risk of tooth loss (Ragnarsson et al., 1992; Holm, 1994; Krall et al., 1997). From the ANCOVA model of the present study, it was also found that smoking was associated with AMT among the 35- to 44year-olds, but not for the 65- to 74-year-olds. This result is similar to the findings from some other studies that smoking as a risk factor for tooth loss was mainly found in younger individuals (Eklund and Burt, 1994; Holm, 1994). The present finding that those who had a more recent dental visit among the 35- to 44-year-olds had a higher AMT than those who had not may be due to the therapeutic rather than the preventive approach adopted by most dentists in Southern China. The questionnaire revealed that, of dental visits during the preceding 2 years, one-fifth of the 35- to 44-year-olds and one-third of the 65- to 74-year-olds reported having received an extraction (Lo et al., 2001).

In the rural areas of Mainland China, there are still many dental care providers who have been trained in traditional apprenticeships rather than in dental schools. These dental care providers mainly provide relief from dental pain, tooth extraction, and prosthetic treatments. For extensive caries, for mobile teeth, and for dentoalveolar infections from endodontic or periodontal origin, these individuals extract the offending teeth, rather than attempting any treatment which would involve the retention of such teeth. They use a variety of materials and often rather special dental prosthetic principles (Luan et al., 1989). They often provide a bridge rather than a partial denture, even though only very few teeth may be retained in an arch. This is the explanation for one of the findings of the present study, namely, the different prosthetic treatment patterns between the urban and the rural residents.

While only $6 \%$ of the 65 - to 74-year-olds were edentulous, even if the teeth indicated for extraction had been removed, $22 \%$ of the elderly had no occluding tooth pairs. This means that $16 \%$ of the 65- to 74-year-olds retained just a few teeth not indicated for extraction, but that these teeth had no occlusal relationship. While $50 \%$ of the 65 - to 74 -year-olds had 20 or more teeth after IMT were accounted for, only $34 \%$ had at least 10 occluding pairs. A count of occluding pairs, after accounting for IMT and considering only those teeth and pontics in function, might give a more meaningful measure of the state of residual dentitions than merely the number of teeth present. This approach has been used in some studies (Battistuzzi et al., 1987; Steele et al., 1997) but not in many. Steele et al. (1997) have proposed, on the basis of their study, that many of the principles of the shortened dental arch are consistent with 
good function in the elderly. It has been proposed that 10 occluding pairs, specifically arranged from premolar to premolar, should satisfy function at a suboptimal but acceptable level for older people (Käyser, 1984, 1989). The numbers of occluding pairs have been shown in the elderly in England to affect their selection of food (Sheiham et al., 1999). In this study, it was found that the elderly residents of Guangdong more commonly reported difficulties in chewing hard foods when they had fewer than 8 occluding tooth pairs. Thus, tooth loss in this population group, when advanced, may adversely affect oral function. Efforts to preserve more natural teeth of the aging people in Southern China, although their tooth loss situation may not be as bad as that in industrialized countries, should center on the prevention of dental caries and periodontal disease, on oral health education in relation to the preventive, rather than the current symptom-driven, use of available dental care services, which so often results in tooth extraction (Lo et al., 2001), and perhaps on the further education of traditional dental care providers in the rural areas, to equip them with the means to treat and retain diseased teeth.

\section{ACKNOWLEDGMENTS}

The University of Hong Kong (CRCG) and the Research Grants Council of Hong Kong financially supported this study.

\section{REFERENCES}

Battistuzzi PG, Käyser AF, Kanters N (1987). Partial edentulism, prosthetic treatment and oral function in a Dutch population. J Oral Rehabil 14:549-555.

Baelum V, Fejerskov O (1986). Tooth loss as related to dental caries and periodontal breakdown in adult Tanzanians. Community Dent Oral Epidemiol 14:353-357.

Baelum V, Luan WM, Fejerskov O, Xia C (1988). Tooth mortality and periodontal conditions in 60-80-year-old Chinese. Scand J Dent Res 96:99-107.

Burt BA, Eklund SA (1992). Dentistry, dental practice, and the community. 4th ed. Philadelphia: W.B. Saunders Company, pp. 52-89.

Chen HM, Zhang JZ, Yi XQ, Pu JT (1986). Report of a sampling investigation on oral health conditions in Chengdu old people. $J$ Clin Stomatol 2:121-125 (in Chinese).

Corbet EF, Davies WIR (1991). Reasons given for tooth extraction in Hong Kong. Community Dent Health 8:121-130.

Corbet EF, Lo ECM (1994). Tooth spaces in and prosthetic treatment received by the middle-aged and the elderly in Hong Kong. Community Dent Oral Epidemiol 22:386-391.

Corbet EF, Wong MCM, Lin HC (2001). Periodontal conditions in adult Southern Chinese. J Dent Res 80:1480-1485.

Downer MC (1991). The improving dental health of United Kingdom adults and prospects for the future. Br Dent $J$ 170:154-158.

Ekanayaka A (1984). Tooth mortality in plantation workers and residents in Sri Lanka. Community Dent Oral Epidemiol 12:128-135.

Eklund SA, Burt BA (1994). Risk factors for total tooth loss in the United States; longitudinal analysis of national data. J Public Health Dent 54:5-14

Gordon PH, Murray JJ, Todd JE (1994). The shortened dental arch: supplementary analyses from the 1988 adult dental health survey. Community Dent Health 11:87-90.

Hawkins RJ (1998) The shortened dental arch: prevalence and normative treatment needs in a sample of older Canadian adults. Spec Care Dentist 18:247-251.

Holm G (1994). Smoking as an additional risk for tooth loss. J Periodontol 65:996-1001.

Kalsbeek H, Truin GJ, Burgersdijk RCW, Van 't Hof MA (1991). Tooth loss and dental caries in Dutch adults. Community Dent Oral
Epidemiol 19:201-204

Käyser AF (1984). Minimum number of teeth needed to satisfy functional and social demands. In: Public health aspects of periodontal disease. Frandsen A, editor. Chicago: Quintessence, pp. 135-147.

Käyser AF (1989). The shortened dental arch: a therapeutic concept in reduced dentitions and certain high risk groups. Int $J$ Periodont Rest Dent 9:426-449.

Krall EA, Dawson-Hughes B, Garvey AJ, Garcia RI (1997). Smoking, smoking cessation, and tooth loss. J Dent Res 76:1653-1659.

Lin HC, Wong MCM, Wang ZJ, Lo ECM (2001a). Oral health knowledge, attitudes, and practices of Chinese adults. J Dent Res 80:1466-1470.

Lin H.C, Wong MCM, Zhang HG, Lo ECM, Schwarz E (2001b). Coronal and root caries in Southern Chinese adults. J Dent Res 80:1475-1479.

Liu DW, Zhu ZL, Dai XJ, Wang LZ, Yan P, Fan ZZ, et al. (1984). A survey of oral health of the children and adults in Chengdu. West China J Stomatol 2:84-89 (in Chinese).

Lo ECM, Schwarz E (1994). Tooth and root conditions in the middle-aged and the elderly in Hong Kong. Community Dent Oral Epidemiol 22:381-385.

Lo ECM, Lin HC, Wang ZJ, Wong MCM, Schwarz E (2001). Utilization of dental services in Southern China. J Dent Res 80:1471-1474.

Loh T, Ow RKK, Neo J, Khoo J, Lim LP (1996). Tooth loss and coronal caries of elderly residents in Singapore. Community Dent Oral Epidemiol 24:300-301.

Luan WM, Baelum V, Chen X, Fejerskov O (1989). Tooth mortality and prosthetic treatment patterns in urban and rural Chinese aged 20-80 years. Community Dent Oral Epidemiol 17:221-226.

Manji F, Baelum V, Fejerskov O (1988). Tooth mortality in an adult rural population in Kenya. $J$ Dent Res 67:496-500.

Marcus SE, Drury TF, Brown LJ, Zion GR (1996). Tooth retention and tooth loss in the permanent dentition of adults: United States, 1988-91. $J$ Dent Res 75(Spec Iss):684-695.

Micheelis W, Bauch J (1996). Oral health of representative samples of Germans examined in 1989 and 1992. Community Dent Oral Epidemiol 24:62-67.

Miller Y, Locker D (1994). Correlates of tooth loss in a Canadian adult population. J Can Dent Assoc 60:549-555.

O'Mullane D, Whelton H, Galvin N (1993). Health services and women's oral health. J Dent Educ 57:749-752.

Petersen PE, Razanamihaja N (1996). Oral health status of children and adults in Madagascar. Int Dent J 46:41-47.

Petersen PE, Kaka M (1999). Oral health status of children and adults in the Republic of Niger, Africa. Int Dent J 49:159-164.

Petersen PE, Peng B, Tai BJ (1997). Oral health status and oral health behaviour of middle-aged and elderly people in PR China. Int Dent $J$ 47:305-312.

Ragnarsson E, Elíasson ST, Ólafsson SH (1992). Tobacco smoking, a factor in tooth loss in Reykjavík, Iceland. Scand J Dent Res 100:322-326.

Schwarz E, Zhang HG, Wang ZJ, Lin HC, Lo ECM, Corbet EF, et al. (2001). An oral health survey in Southern China, 1997: background and methodology. $J$ Dent Res 80:1453-1458.

Sheiham A, Steele JG, Marcenes W, Finch S, Walls AW (1999). The impact of oral health on stated ability to eat certain foods; findings from the National Diet and Nutrition Survey of Older People in Great Britain. Gerodontology 16:11-20.

Spencer AJ, Davies M, Slade G, Brennan D (1994). Caries prevalence in Australasia. Int Dent $J$ 44:415-423.

Steele JG, Ayatollahi SM, Walls AW, Murray JJ (1997). Clinical factors related to reported satisfaction with oral function amongst dentate older adults in England. Community Dent Oral Epidemiol 25:143-149.

White BA, Caplan DJ, Weintraub JA (1995). A quarter century of changes in oral health in the United States. J Dent Educ 59:19-57.

Witter DJ, van Palenstein-Helderman WH, Creugers NH, Käyser AF (1999). The shortened dental arch concept and its implications for oral health care. Community Dent Oral Epidemiol 27:249-258.

World Health Organization (1997). Oral health surveys: basic methods. 4th ed. Geneva: WHO. 